\title{
Oh bondage! Up yours! Sexualidades dissidentes e manifestações não normativas do desejo na obra de Hito Steyerl
}

Gabriela Machado Ramos de Almeida

Centro Universitário Ritter dos Reis - UniRitter, Porto Alegre, Rio Grande do Sul, Brasil

Jamer Guterres de Mello

Universidade Anhembi Morumbi - UAM, São Paulo, São Paulo, Brasil

\section{Resumo}

Este artigo discute as possibilidades de agenciamento de uma sensibilidade queer em diálogo com os feminismos dissidentes no documentário Lovely Andrea, produzido em 2007 pela artista e pesquisadora alemã Hito Steyerl. O filme mostra a autora no Japão, em busca de uma fotografia de si mesma feita 20 anos antes, em um ritual de bondage. $\mathrm{O}$ artigo se baseia principalmente nas contribuições teóricas da própria Steyerl (2010, 2012, 2014, 2015), Preciado (2008, 2015) e Berardi (2016) para acionar um debate sobre manifestações não normativas do desejo, práticas sexuais dissidentes e política das imagens.

\section{Palavras-chave}

Dissidências sexuais e de gênero. Sensibilidade queer. Estética da resistência. Hito Steyerl.

\section{Introdução}

O documentário Lovely Andrea (Alemanha, 30'), produzido em 2007 pela artista, ensaísta e professora alemã Hito Steyerl, foi exibido prioritariamente em circuitos expositivos de arte contemporânea, como galerias, museus e bienais. A obra, que em um primeiro olhar assemelha-se a um documentário autobiográfico ou a um filme de busca, aborda a procura de Steyerl por uma foto de si mesma em um ensaio fotográfico de bondage, do qual participou 20 anos antes no Japão, no período em que viveu no país para estudar cinema. Embora pareça impossível de ser localizada em meio a milhares de publicações japonesas sobre bondage produzidas ao longo de décadas, a fotografia opera no filme como disparadora de questionamentos a respeito de manifestações não normativas do desejo e de práticas contrassexuais (PRECIADO, 2015).

Comissionada para a $12^{a}$ edição da Documenta, considerada a exposição de artes 
visuais mais importante do mundo, a realização de Lovely Andrea ${ }^{1}$ dialoga de forma bastante próxima com os escritos da própria Hito Steyerl, que vem produzindo há pelo menos 10 anos ensaios sobre artes, imagens e suas relações com o capitalismo, publicados de forma dispersa em sites como $e$-flux ou, mais recentemente, em livros de compilação desses textos (STEYERL, 2012, 2014).

Percebemos o filme como motivo para discutir de forma bastante potente as relações entre feminismos e representações da sexualidade e situamos Hito Steyerl como artista e autora que pode ser lida a partir da chave dos chamados feminismos dissidentes, que se produziram, desde os anos de 1980, como resposta aos "sucessivos descentramentos do sujeito mulher que, de maneira transversal e simultânea, questionam o caráter natural e universal da condição feminina" (PRECIADO, 2008, p. 236, tradução nossa²), ou seja, quando o sujeito político do feminismo hegemônico é colocado sob suspeita (COELHO, 2009).
Esses feminismos dissidentes fizeram frente ao feminismo antissexo norte-americano da década de $1970^{3}$, que tomava a pornografia necessariamente como ferramenta de opressão, violência e dominação das mulheres e defendia a censura total às representações visuais do sexo. A partir dos anos de 1980, críticas a essa vertente passaram a aparecer, atualizando o debate sobre a relação entre feminismo, trabalho sexual e pornografia e afirmando que a defesa da censura e do fim da pornografia devolvem ao Estado, afinal, o poder de regulamentar as representações da sexualidade e concedem ainda mais poder a uma instituição ancestral de origem patriarcal (PRECIADO, 2008). Os feminismos dissidentes afirmaram, naquele momento, que o Estado não pode proteger os indivíduos da pornografia "porque a descodificação da representação é sempre um trabalho semiótico aberto de que não se há de prevenir, mas sim atacar com reflexão, discurso crítico e ação política" (PRECIADo, 2008, p. 238, tradução nossa4).

10 filme está disponível na íntegra no portal UbuWeb <http://www.ubu.com/film/steyerl_andrea.html>. Acesso em: 24 fev. 2018.

2 "[...] sucesivos descentramientos del sujeto mujer que de manera transversal y simultánea cuestionarán el caracter natural y universal de la condición femenina".

3 Também chamado de feminismo abolicionista, por defender a extinção total da pornografia e da prostituição.

4 " [...] porque la descodificación de la representación es siempre un trabajo semiótico abierto del que no hay que prevenirse, sino al que hay que atacar con reflexión, discurso crítico y acción política". 
Propomos, aqui, uma aproximação entre os feminismos dissidentes e as micropolíticas queer como forma de analisar um documentário feito por uma artista mulher ocidental, de ascendência oriental, que aborda uma experiência pessoal vivida no Oriente envolvendo o bondage ${ }^{5}$, e cuja abordagem, no filme, não é estigmatizada ou esvaziada como mera violência de gênero.

Embora Hito Steyerl não se autodefina como feminista dissidente ou situe Lovely Andrea no pós-pornô ${ }^{6}$, consideramos que sua obra dialoga com aquilo a que Preciado se refere como um "feminismo lúdico e reflexivo que escapa ao âmbito acadêmico para encontrar na produção audiovisual, literária ou performativa seus espaços de ação" (PRECIADO, 2007, tradução nossa ${ }^{7}$ ). Para a autora, “o melhor antídoto contra a pornografia dominante não é a censura, mas a produção de representações alternativas da sexualidade, feitas a partir de olhares divergentes dos pontos de vista normativos" (PRECIADO, 2007, tradução nossa ${ }^{8}$ ).

O artigo se baseia, assim, em algumas noções desenvolvidas pe=la própria Hito Steyerl, como imagem ruim ${ }^{9}$ (2015), capitalismo audiovisual (2015) e circulacionismo (2014), bem como nas contribuições de Franco Berardi (2016) sobre semiocapitalismo, e de Beatriz Preciado ${ }^{10}$ com sua contextualização histórica dos feminismos dissidentes e das

5 Bondage é uma técnica específica de fetiche de inspiração japonesa que consiste em amarrar e imobilizar o parceiro, criando uma relação de dominação e submissão. No entanto, termos como Shibari e Kinbaku também se referem a esta prática, com algumas distinções sutis que serão exploradas no artigo.

60 pós-pornô (ou pós-pornografia) engloba obras, performances e ações pós-pornográficas com o objetivo comum de confrontar "o imaginário pornográfico e sexual vigente a partir da representação de corpos, gêneros e práticas sexuais historicamente marginalizadas, juntamente com a recusa dos discursos, estéticas e narrativas tradicionais da pornografia comercial, heterossexualmente orientada" (SARMET, 2014, p. 259).

7 No original: "feminismo lúdico y reflexivo que escapa del ámbito universitario para encontrar en la producción audiovisual, literaria o performativa sus espacios de acción".

8 "el mejor antídoto contra la pornografía dominante no es la censura, sino la producción de representaciones alternativas de la sexualidad, hechas desde miradas divergentes de la mirada normativa".

9 Ou imagem "pobre", na tradução que o termo ganhou para o espanhol a partir do original inglês "poor image".

10 Segundo Preciado, um dos princípios da sociedade contrassexual seria desestabilizar o sistema heterocentrado utilizando alternativamente um nome do sexo oposto para evitar a reapropriação dos corpos como feminino ou masculino no sistema social (PRECIADO, 2015). Para a autora, há um conjunto arbitrário de regulações que operam diretamente nos corpos atribuindo papéis sexuais aos gêneros masculino e feminino, pois o sexo é uma tecnologia biopolítica de dominação social heteronormativa que cria a produção de feminilidade e masculinidade por divisão e fragmentação do corpo (PRECIADO, 2015). Ser homem ou mulher é uma ficção somaticopolítica produzida por diferentes formas de domesticação que acabam distorcendo nossa realidade (PRECIADO, 2008). Assim, decidimos utilizar a denominação correspondente à forma como a autora se identificava à época em que os livros utilizados 
micropolíticas queer (2008) e com o Manifesto contrassexual (2015).

Diante da ausência de estudos sobre Hito Steyerl no campo da Comunicação no Brasil tanto de sua produção artística quanto escrita - consideramos importante contextualizar a produção da artista elencando e tensionando algumas de suas ideias e obras mais relevantes para a pesquisa aqui apresentada. Não foram localizados artigos dedicados à obra artística de Steyerl nos anais de eventos como os congressos anuais da Compós, socine e Intercom, bem como no Google Acadêmico. Há alguns poucos artigos que se valem de conceitos da autora, especialmente o de imagem ruim, publicados em periódicos brasileiros. Não encontramos, no entanto, nenhum trabalho mais exaustivo publicado no Brasil em forma de artigo dedicado a uma análise da sua contribuição recente à prática e à teoria do audiovisual.

O artigo está estruturado, então, da seguinte forma: em um primeiro momento, o trabalho teórico e artístico de Steyerl é abordado brevemente, com o objetivo de apresentar as articulações que tenta produzir entre esses dois âmbitos. Em seguida, procedemos à abordagem do documentário Lovely Andrea, com o objetivo de discutir o modo como o filme coloca em questão a política das imagens, as estruturas de poder, a liberdade sobre o corpo e o bondage como trabalho, arte e cultura, a despeito do caráter de tabu no mundo ocidental em relação a tudo que envolve as práticas BDSM (entre as quais o bondage se inscreve), especialmente as funções e papéis das mulheres em vivências sexuais que envolvem submissão voluntária e pornografia, e que são alvo de polêmicas históricas no feminismo.

Serão explorados aspectos do filme que revelam na obra artística de Hito Steyerl aquilo a que ela se refere em um de seus ensaios como estética da resistência (STEYERL, 2010). Algumas perguntas despertaram o interesse na realização desta pesquisa e norteiam a execução do trabalho: é possível pensar em mecanismos estéticos de resistência às normatividades sexuais no capitalismo? Tais mecanismos seriam passíveis de provocar rupturas que desestabilizam algumas instituições hegemônicas de disciplina e controle? Ou talvez rupturas na forma como o próprio desejo feminino é percebido pelo senso comum e, muitas vezes, pelo feminismo? A submissão voluntária proposta pelo bondage pode funcionar 
como potência de transformação e autonomia sobre o corpo? O que a fetichização dos corpos no bondage nos diz? É possível pensar, afinal, em uma sensibilidade queer em diálogo com os feminismos dissidentes nessa representação do bondage que é produzida no documentário Lovely Andrea?

\section{Hito Steyerl entre a realização artística e a produção teórica}

Artista, escritora, ensaísta e professora de cinema e vídeo experimental na Universität der Künste Berlin"11, Hito Steyerl foi eleita, em 2017, a artista mais influente do mundo pela revista britânica ArtReview, que publica anualmente o ranking Power 100, dedicado a elencar os artistas contemporâneos que a revista considera, de acordo com critérios próprios, os mais importantes do mundo. Steyerl foi a primeira mulher a alcançar essa posição desde a criação do ranking, em 2002. É curioso que figure no topo dessa lista, uma vez que sua obra é marcada por uma forte crítica às formas instituídas de poder e dominação econômica, política e simbólica, inclusive aquelas do próprio campo da arte (da qual fazem parte suas instâncias de consagração e reconhecimento, como os espaços da crítica e o circuito expositivo). Esse reconhecimento parece mais facilmente compreensível, no entanto, quando se considera a possibilidade de que sua obra adquira importância no circuito da arte contemporânea justamente pelo seu teor político em um contexto de apropriação das ideologias pelo capital (cenário do qual ela demonstra ser totalmente consciente).

Com uma produção artística voltada ao vídeo e um trabalho teórico dedicado à política das imagens, Steyerl teve sua primeira exposição de maior repercussão em 1999, na Bienal de Viena. Desde então, participou de dezenas de mostras coletivas em exposições de artes e teve sua obra exibida também em festivais de cinema. Passou a produzir trabalhos comissionados, a exemplo do curta-metragem documental que é objeto de análise neste artigo, Lovely Andrea, e a videoinstalação Hell Yeah We Fuck Die, para a 32 $2^{a}$ Bienal de São Paulo, em $2016^{12}$.

O trabalho artístico de Hito Steyerl, de um modo geral, é composto de obras em vídeo em diferentes formatos, desde curtas-metragens colhidas no site: <https://www.udk-berlin.de/en/people/detail/person/hito-steyerl/>. Acesso em: 30 jan. 2018. 
para serem exibidos em um único canal em projeção de vídeo - como é o caso de Lovely Andrea -, até obras instalativas mais complexas, com múltipla composição de telas, objetos e diferentes formas de projeção. É comum o uso de imagens em baixa resolução, de imagens de arquivos públicos ou privados, de dados digitais que remetem ao mundo hiperconectado, de linguagem própria da cultura pop, com o uso de cores saturadas, referências ao punk e a filmes de artes marciais. Em grande parte de suas obras, há também o uso da narração como recurso discursivo e estilístico com papel fundamental na construção de um comentário crítico sobre estética, política, economia, guerras e um conjunto de temas tratados quase sempre por um ponto de vista também teórico.

Os campos artístico e acadêmico (especialmente das Teorias da Arte e das Teorias das Mídias, nos quais seus escritos mais circulam) costumam referir-se à obra videográfica e teórica de Hito Steyerl como ensaios, dado o seu caráter metarreflexivo e a tentativa constante de levar a sua produção escrita a pensar o seu fazer artístico e, de forma mais ampla, pensar como a circulação das imagens transcende as próprias imagens e seus impactos se manifestam no mundo no que ela chama de capitalismo audiovisual. Ela mesma assume o ensaio como forma possível de investigação artística, tanto em sua expressão fílmica quanto textual, baseada em Hans Richter, para quem o ensaio no cinema é uma linguagem que poderia tornar perceptíveis pensamentos e até ideias, e que daria visibilidade ao que não é visível, dando forma a um conteúdo intelectual. Segundo Richter, ao ensaio é permitido "utilizar tudo, o que existe e o que se inventa, desde que sirva como argumento para tornar visível o pensamento de base" (RICHTER, 2007, p. 188, tradução nossa ${ }^{13}$ ).

Fazem parte do conjunto de interesses de Steyerl, expressos por meio de escritos e obras audiovisuais com forte inflexão ensaística, a biopolítica e os atravessamentos do capitalismo no cotidiano, manifestados na cultura, vigilância, militarismo, violência, militâncias, economia e em relações de trabalho e de gênero. Ela trabalha a partir da premissa de que as tecnologias de comunicação global e as formas de mediação promovidas pelas imagens afetam as concepções vigentes de governabilidade, cultura, economia e subjetividade. Partindo de conceitos como pós-cinema, de Steven Shaviro, e pós-produção, de Nicolas 
Bourriaud, Steyerl conclui que haveria uma carga de violência que se instala no interior das imagens e que se reproduz a partir da comunicação em rede e das estratégias contemporâneas de distribuição da informação.

Seu trabalho videográfico transita entre o documentário, a videoinstalação, o cinema experimental e a cultura digital. Como artista e teórica, vem tentando produzir uma cartografia da produção midiática em tempos de capitalismo audiovisual ou, segundo Franco Berardi, "uma cartografia de uma nova sensibilidade emergente" (2014, p. 13, tradução nossa ${ }^{14}$ ). Tanto os textos quanto os vídeos de Steyerl tentam dar conta de um contexto amplo, que ela nomeia de capitalismo audiovisual, em que estética e política não podem ser dissociadas e em que as imagens estão inscritas em um regime visual e econômico do qual fazem parte diversos dispositivos institucionais (inclusive a televisão, o museu e o cinema). As imagens são, no contexto do capitalismo audiovisual, um ambíguo veículo de produção de relações sociais que funciona tanto como mercadoria quanto como meio expressivo e de enunciação política (STEYERL, 2015).
A ideia de capitalismo audiovisual aparece no ensaio Em defesa da imagem ruim (2015), um dos mais conhecidos textos de Steyerl ${ }^{15}$. Partindo da premissa de que haveria uma "sociedade de classe das imagens" baseada principalmente na fetichização da alta resolução como sinônimo de qualidade, bem fazer e raridade (uma vez que, quanto maior a resolução, mais difícil de copiar as imagens, pirateá-las e fazê-las circularem nos meios digitais), a autora afirma que a imagem ruim é uma imagem de baixa resolução, "o fantasma de uma imagem, uma pré-imagem, uma miniatura, uma ideia errante, uma imagem itinerante", "um trapo ou um resto":

Ela [a imagem ruim] transforma qualidade em acessibilidade, valor de exposição em valor de prestígio cult, filmes em clipes, contemplação em distração. A imagem é liberada dos arquivos e dos cofres das cinematecas e atirada na incerteza digital, às custas de sua própria substância. A imagem ruim tende à abstração: é uma ideia visual em seu próprio devir. (STEYERL, 2015, p. 187).

Para Steyerl, que toma o semiocapitalismo ${ }^{16}$ como episteme, vivemos em um contexto no qual a imagem é também moeda e toda

14 "[...] una cartografía de la nueva sensibilidad emergente".

15 É um dos poucos traduzidos para o português até o momento, publicado na revista serrote (edição de março de 2015). Intitulado originalmente In Defense of the Poorlmage, o ensaio foi publicado originalmente no site e-flux e depois no livro The Wretched of the Screen, que reúne diversos textos da autora. Referência: STEYERL, 2012. 
a produção de subjetividades passa pela produção e consumo de imagens. Uma vez que esses processos de produção e consumo obedecem a uma lógica capitalista, seria necessário questionar o que tem acontecido com a subjetividade, a sensibilidade, a capacidade de imaginar, criar e inventar, ou seja, pensar em novas formas de resistência aos dogmas capitalistas em um momento em que a história sem sido substituída pelo infinito fluxo recombinatório de imagens fragmentárias.

Essas formas possíveis de resistência comporiam uma espécie de desobediência epistêmica: "Era necessário resistira um poder/saber/arte - que reduzia populações inteiras a objetos de conhecimento, dominação e representação não apenas através da luta social e da revolta, mas também através da inovação epistemológica e estética" (STEYERL, 2010, tradução nossa $\left.{ }^{17}\right)$. O objeto imaterial se adapta à semiotização do capital e a imagem ruim, enquanto objeto imaterial, guarda em si uma ambiguidade: trabalha contra a fetichização da alta resolução e, justamente por isso, se integra ao semiocapitalismo. A imagem ruim é, no final das contas, desobediência e obediência epistêmica na mesma medida:

Imagens ruins são, portanto, imagens populares - imagens que podem ser feitas e vistas por muita gente. Elas expressam todas as contradições da multidão contemporânea: seu oportunismo, seu narcisismo, seu desejo de autonomia e de criação, sua incapacidade de se concentrar ou se decidir, sua constante prontidão para a transgressão e a simultânea submissão. Em última análise, as imagens ruins apresentam um instantâneo da condição afetiva da multidão, sua neurose, sua paranoia, seu medo, assim como seu anseio por intensidade, diversão e distração. (STEYERL, 2015, p. 194).

Embora Steyerl não defina nesses termos, é possível considerar o capitalismo audiovisual como uma espécie de braço do semiocapitalismo, uma esfera em que o signo de que Franco Berardi fala é a imagem. Essa constatação conduz a outra ideia desenvolvida pela artista em seus escritos e que se torna importante para esse trabalho, o circulacionismo.

todo ato de transformação pode ser substituído por informação e o processo de trabalho se realiza através da recombinação de signos" (BERARDI, 2016, p. 109, tradução nossa), e esta se torna, então, o ciclo principal da economia. 0 conceito dialoga com as proposições dos autores que tratam do capitalismo cognitivo, como Maurizio Lazzarato e Antonio Negri, e falam de produção imaterial e trabalho imaterial para "explicar o fato de que na esfera pós-industrial a produção de valor se determina sobretudo através do pagamento de uma atividade não física que se deposita em objetos privados de caráter físico", conforme Berardi (2016, p. 109).

17 "Había que contrarrestar a un poder/saber/arte - que reducía a poblacion es enteras a objetos de conocimiento, dominación y representación - no sólo a través de la lucha sociy la revuelta, sino también mediante la innovación epistemológica y estética". 
Trata-se do termo a partir do qual Steyerl trabalha a ideia de que quanto mais uma imagem se movimenta e circula em meios digitais ou físicos - especialmente a imagem ruim - mais poder ela acumula. Se tornou também título de uma exposição de obras da autora realizada no México e de um livro/ catálogo lançado por ocasião da mostra ${ }^{18}$. Se a produção e o consumo de imagens não apenas acontecem no semiocapitalismo como também são dele um agente, as imagens são agentes igualmente das estratégias de ação biopolítica que resultam nas mais diversas formas de violência.

Essa relação deriva do fato de que, além da resolução e do valor de troca, as imagens passam a ter também um valor de velocidade acionado pela intensidade e pela difusão: "As imagens são ruins porque foram muito comprimidas e viajam mais depressa. Elas perdem matéria e ganham velocidade" (STEYERL, 2015, p. 194). Também expressam uma condição de desmaterialização que está associada ao que Berardi chama de "aceleração semiótica”, processo segundo o qual o aumento "em excesso dos signos que demandam ser interpretados ou, melhor dizendo, consumidos por parte do mercado social da atenção, leva a um efeito de saturação da atenção" (BERARDI, 2016, p.111, tradução nossa ${ }^{19}$ ). Esse estado geral aparece não apenas nos escritos da artista, mas também em sua obra em vídeo, em diferentes momentos que se interrelacionam e que dizem respeito ao filme que será analisado na seção seguinte: a própria obra de Steyerl é composta de imagens pobres e atravessada pelo circulacionismo.

Steyerl desenvolveu uma videoinstalação chamada O museu é um campo de batalha?2o, em que relaciona o museu a um campo de batalha e faz parte da exposição intitulada Circulacionismo. O vídeo aponta uma discussão também presente em seus trabalhos e escritos anteriores sobre o museu como espaço de dominação e de disputas de ordem política e econômica. Ela tenta compreender seu próprio papel enquanto artista que expõe em museus quando descobre, por exemplo, que a empresa fabricante de munição Lockheed Martin, agente fulcral dos conflitos armados no Oriente Médio, é também financiadora de exposições de arte e museus nos quais sua

18 Referência: STEYERL, 2014.

19 "[...] en exceso los signos que requieren ser interpretados o, major dicho, consumidos por parte del mercado social de la atención, lleva a un efecto de saturación de la atención".

20 Ela havia publicado, anteriormente, um ensaio em que questionava se o museu era uma fábrica, intitulado Is museum a factory? (STEYERL, 2012). 
obra é exposta e em que já esteve ministrando conferências (a exemplo da Bienal de Istambul e do Art Institute of Chicago).

Durante uma pesquisa de campo para o documentário que realizaria sobre uma amiga, Andrea Wolf, que foi assassinada como terrorista em 1998, depois de deixar a Alemanha dois anos antes para viver na região do Curdistão e integrar exército feminino do Partido dos Trabalhadores Curdos, Steyerl usou um celular para registrar a si mesma recolhendo cartuchos usados de mísseis disparados por helicópteros na Turquia, na província de Van, próxima à fronteira com o Irã e o Iraque (região em que vive a população curda). Essa munição que matou Andrea Wolf e que a artista encontrou era produzida, no entanto, pela mesma Lockheed Martin que patrocina o museu em que esse mesmo documentário, intitulado November: a film treatment, foi exibido pela primeira vez.

A partir dessa constatação, Hito Steyerl desenvolveu a ideia de uma munição que viaja em círculos e cujos tiros são disparados em diferentes locais mas acabam por circular dos campos de batalha para diversos museus, e dos museus de volta aos campos de batalha:
"A viagem dessa bala invisível é um elemento central do circulacionismo"21. O colecionismo não é a arte de criar imagens, mas sim de pós-produzi-las, lançá-las e acelerá-las (STEYERL, 2014), fazendo com que ganhem vida fora $d a$ tela no capitalismo audiovisual.

Essa vida fora da tela acontece com as próprias imagens de Andrea, que aparece em November: a film treatment em imagens de arquivo do acervo pessoal de Steyerl, que havia feito aos 17 anos um filme feminista amador de artes marciais, no qual ambas - Andrea e Steyerl - atuam como protagonistas. Andrea, no entanto, vai reaparecer em Lovely Andrea não apenas na menção evidente ao seu nome no título, mas porque Steyerl assume uma personagem de nome Andrea em sua performance de bondage que foi fotografada e publicada na revista japonesa que ela vai procurar 20 anos depois. A artista descobre, ainda, que a imagem da amiga que morreu assassinada passou a ser utilizada pelos curdos em cartazes e manifestações, transformando Andrea em uma espécie de mártir (talvez pelo apelo internacional provocado pela morte de uma alemã que decidiu voluntariamente integrar o exército feminino e o Partido dos Trabalhadores Curdos). 


\section{Bondage: prática sexual, performance e representação}

Lovely Andrea apresenta Hito Steyerl empenhada na busca por uma fotografia de seu passado, uma imagem publicada em uma revista no Japão que mostra a artista em um ensaio fotográfico de bondage, prática conhecida tradicionalmente no país como Shibari (ou Nawa Shibari). Algumas explicações sobre os termos utilizados para descrever práticas associadas ao BDSM e uma contextualização do Shibari são importantes como preâmbulo à análise do filme, uma vez que o trabalho se propõe a pensar em uma possível sensibilidade queer e feminista em uma obra cuja temática, num primeiro olhar, pode remeter apenas às formas mais banalizadas de pornografia com as quais o bondage, por sua vez, é comumente confundido. É preciso levar em consideração que o bondage existe de diversas formas:

1. Como prática sexual, na relação entre duas ou mais pessoas que praticam ritos de amarração, dominação e suspensão, podendo se dar de forma privada ou pública;
2. Enquanto performance e trabalho, em apresentações e shows em casas noturnas especializadas ${ }^{22}$, podendo ou não envolver sexo;

3. Como representação, através de registros fotográficos e audiovisuais que encenam o bondage, bem como em ilustrações e nos quadrinhos.

Em japonês, Nawa é a palavra correspondente para corda e Shibari tem origem no verbo amarrar, sendo ambas associadas a situações do cotidiano que remetem a nós e amarrações, termos não necessariamente ligados ao erotismo ${ }^{23}$. De um modo geral, cordas e ataduras possuem uma forte presença na história e na cultura do Japão, sendo muito comuns na religião, no teatro e nas artes marciais. A palavra Shibari pode ser usada tanto para o ato de amarrar os cadarços de um sapato quanto em um contexto erótico.

É mais comum, no entanto, o uso da palavra bondage, em inglês, ou da expressão bondage japonês erótico, para denominar as mais distintas técnicas de escravidão com cordas,

22 Existem alguns festivais anuais de premiação e apresentação da arte do bondage, como o London Festival of the Art of Japanese Bondage, que se consolidou com um importante espaço de divulgação do trabalho de performers do mundo todo.

23 Há uma espécie de Wikipedia do bondage japonês, chamada Nawa Pedia, que compila e disponibiliza informações em língua inglesa sobre esse universo. Disponível em: <http://www.nawapedia.com/index.php?title=Main_Page>. Acesso em: 07 fev. 2018. 
geralmente com apelo sadomasoquista. É uma prática que incorpora aspectos da cultura milenar oriental e que vem sendo cada vez mais utilizada, tanto como princípio de prazer no âmbito privado das relações sexuais, quanto em um contexto artístico e mercadológico, acionando elementos da performance, da dança e do teatro. No Ocidente, nas últimas décadas, o bondage cresceu em popularidade e é muito comum que uma estética evocada pelo bondage apareça em galerias de arte, nas revistas de moda, na cultura pop ${ }^{24}$ e também na pornografia, além de ter se tornado uma das práticas mais populares entre os praticantes de BDSM.

No site do FetLife, ${ }^{25}$ rede social para pessoas interessadas em BDSM e fetichismo e que se descreve "como o Facebook, mas criada por pervertidos como você e eu", há um conjunto de informações estatísticas, dando conta de mais de seis milhões de usuários que compartilham quase 34 milhões de fotografias e 500 mil vídeos, e que participam de oito milhões de discussões em 116 mil grupos, com mais de 600 mil eventos futuros. $\mathrm{Na}$ página inicial consta o seguinte slogan: "O paraíso da perversão!”. O acionamento de uma chave (a perversão) que associa no senso comum o BDSM ao desvio, à anormalidade e à patologia diz de alguns equívocos e estigmas que se consolidaram em torno de práticas contrassexuais (aquelas que escapam ao sistema reprodutivo heterocentrado), como o bondage.

O BDSM, de forma mais ampla, é uma sigla que conjuga a denominação de três duplas de práticas sexuais consideradas por Gayle Rubin (1989) como sexualidades dissidentes ou dissidentes eróticos, aqueles comportamentos que estavam à margem do sistema normativo como as práticas sexuais não reprodutivas, homossexuais, poligâmicas, intergeracionais, pornográficas, sadomasoquistas, entre outras. A partir de Foucault (1988) e seus escritos nos volumes de História da sexualidade, Rubin (1989) critica a visão tradicional da sexualidade como impulso natural da libido. A sigla BDSM é dividida, então, em Bondage e Disciplina (BD), Dominação e Submissão (DS) e Sadismo e Masoquismo ( $\mathrm{SM}$ ), além de incorporar também algumas outras práticas eróticas de fetichismo, em geral engendradas por uma pessoa na condição de dominação e outra na de

24. De forma "domesticada", em função da popularidade de séries de livros e filmes como Cinquenta tons de cinza e outros produtos semelhantes.

25 Disponível em: <https://fetlife.com>. Acesso em: 08 fev. 2018. 
submissão. É Georges Bataille quem diz que "essencialmente, o domínio do erotismo é o domínio da violência, o domínio da violação" (BATAILlE, 1987, p. 16).

O bondage, então, é uma prática japonesa derivada do Shibari, que utiliza a amarração com cordas com o objetivo de imobilizar e restringir as ações e movimentos da pessoa dominada, produzindo uma série de estímulos sensoriais que podem ou não estar relacionados ao erotismo e ao sexo. A Disciplina é um dos elementos essenciais do bondage, em que o submisso é ensinado a obedecer seu dominador a partir do castigo. Dominação e Submissão são atividades utilizadas para demarcar o poder do dominador e o consentimento do submisso de ser controlado como escravo. Sadismo e Masoquismo são práticas relacionadas a ações físicas com o objetivo de causar ou receber dor e que proporcionam prazer tanto para o dominador quanto para o submisso.

As práticas de BDSM formam um conjunto bastante variado de experimentações e sensações eróticas em partes distintas do corpo, não apenas em zonas erógenas ou em órgãos genitais e não necessariamente envolvem o ato sexual com penetração. A presença e o uso do corpo são essenciais no BDSM e requerem um trabalho minucioso e detalhado por parte dos praticantes, a partir de experiências bastante íntimas e pessoais. É possível afirmar que o BDSM e a exploração de sensações e estímulos eróticos nos corpos dos participantes causam uma espécie de desvio daquilo que é definido como norma sexual, ou seja, as práticas sexuais tradicionais heteronormativas.

Ao comparar-se a obra de Masoch com a de Sade, é-se surpreendido pela impossibilidade de um encontro entre um sádico e um masoquista. Seus meios, suas cerimônias diferem inteiramente; suas exigências nada têm de complementar. A inspiração de Sade é antes de tudo mecanicista e instrumentalista. A de Masoch é profundamente culturalista e estética (DELEUZE, 2017, p. 95).

No entanto, embora o bondage esteja intimamente ligado à sigla BDSM e, por consequência, às práticas de sadismo e masoquismo, as técnicas japonesas do Shibari não pressupõem a priori um princípio de frieza, elemento que Deleuze (2009, p. 116) descreve como essencial "tanto na apatia sádica quanto no ideal do frio masoquista", segundo sua interpretação das teses freudianas. O bondage é, portanto, uma prática que se sobressai ao amplo conjunto constituído pelo BDSM, possui uma complexa estrutura histórica e teórica e, mais do que isso, é parte de um amplo processo cultural e ancestral. 
Sobre a ancestralidade do bondage japonês, o Nawashi26, Haruki Yukimura, um dos especialistas em Shibari de maior reconhecimento do Japão, afirma que:

existe uma cultura milenar de corda no Japão: quimonos, plantas e presentes são amarrados. [...] até na bainha das espadas existiam cordas. [...] No Ocidente, a princesa que vai ser salva é colocada numa prisão, no alto de uma torre; enquanto que no Japão, ela está amarrada. [...] existe uma grande quantidade de histórias japonesas que contemplam amarrar as pessoas: e existem muitas mulheres querendo ser amarradas. [...] a relação do japonês em suportar sofrimento é algo bom, é algo belo: é uma característica nacional encarada com orgulho ${ }^{27}$.

O contexto histórico e cultural das técnicas de amarração com cordas não apenas é importante para os japoneses, como é onipresente nas práticas e nas representações do bondage no Japão. É preciso considerar que os aspectos culturais e artísticos, os fetichistas e sexuais e as formas como os modos de apreciação estética do bondage são percebidos de modos bastante distintos no Japão e no Ocidente.
As cordas e as amarrações representam elementos de muita importância em várias atividades ligadas ao xintoísmo e ao budismo, as duas religiões (ou espiritualidades) mais comuns no Japão, desde cerimônias de purificação até rituais para obter prosperidade. O importante aqui é perceber que as distinções entre a cultura japonesa e as sociedades ocidentais - baseadas em crenças judaico-cristãs - ocorrem em medidas semelhantes tanto em relação à espiritualidade quanto em relação às orientações e normas sexuais. Isso não quer dizer que normatividades não existam no Japão, mas que a percepção sobre ideias como pecado e culpa associadas ao sexo nas culturas ocidentais não existe na tradição japonesa (FRANCOEUR; NOONAN, 2004). Entre as nações industrializadas, o Japão é o único grande país que não demonizou a sexualidade sob a condição do pecado (FRANCOEUR; NOONAN, 2004).

As experiências corporais do Shibari estão vinculadas a uma dimensão transcendental que é parte constitutiva da forma por meio da qual os nipônicos processam, interpretam

26 Nawashi (nawa, que como foi dito significa corda e shi, que significa ofício) ou Bakushi (baku, que significa restrição e shi, que significa ofício) são mestres ou artistas das cordas, especialistas em amarração, aqueles que possuem o conhecimento específico e que amarram seus escravos submissos em sessões de Shibari. Na cultura ocidental do bondage, o Nawashi é conhecido como Ropemaster.

27 Fala extraída do documentário Kinbaku - The Art of Bondage (Jouni Houkkanen, Finlândia, 2010, 29') transcrita e publicada no site Arte Shibari Brasil. 0 texto não tem indicação de autoria ou data e está disponível em: <http://www. arteshibaribrasil.com.br/historia/historia-shibari/>. Acesso em: 11 fev.2018. 
e se relacionam com o mundo. Assim, os elementos que remetem ao poder, à submissão, à beleza e à dominação possuem uma capacidade de produzir efeitos que extrapolam a ideia de fetiche. A corda funciona como uma extensão do dominador, como um elo de comunicação. A ação e o olhar do dominador se fundem à corda e operam como um encontro entre os corpos, como um verdadeiro contato físico-corporal produzido pelas cordas.

No início do século XX a técnica de amarração do Shibari começou a sofrer algumas mudanças de ordem estética e formal e os ritos passam a ser utilizados, sobretudo, para fins artísticos. A partir daí a técnica Shibari passou a ser denominada também como Kinbaku. É atribuída ao mestre japonês Ito Seiu, no período pós-Segunda Guerra Mundial, a construção de uma base técnica, estética e teórica do bondage, inclusive com a produção de fotografias, gravuras e livros, motivo pelo qual ele é geralmente reconhecido como o pai do Shibari/Kinbaku modernos. Apesar de não ser o criador da técnica originalmente, o reconhecimento acontece por Seiu ter desenvolvido as condições para que a amarração com cordas fosse considerada uma forma de arte. Na década de 1960, a partir dos esforços de Seiu e com a soma do trabalho de outros mestres Nawashis, o Kinbaku passou a ser reconhecido como tradição japonesa da arte da submissão sexual através de cordas.

\section{Corpo, desejo e sexualidades dissidentes em Lovely Andrea}

Em Lovely Andrea, Hito Steyerl inicia sua investigação em Hamburgo, na Alemanha, na busca pela fotografia feita em 1987. Recorre ao alemão Matthias T. J. Grimme, escritor, fotógrafo e editor de revistas de sadomasoquismo, conhecedor da cultura japonesa e do universo BDSM, que apresenta à artista algumas imagens de bondage e avisa da dificuldade que Steryerl encontrará para localizar a fotografia, mesmo voltando a Tóquio, uma vez que se passaram 20 anos e cerca de 100 revistas de fotografias envolvendo BDSM são publicadas mensalmente no Japão.

O diálogo inicial do filme, entre Steyerl e Grimme, funciona como uma espécie de introdução, revelando o tom daquilo que o filme reserva ao espectador em termos estéticos e narrativos: imagens de baixa resolução - imagens ruins; uso de canções punk como música extradiegética; um dispositivo discursivo baseado em entrevistas; imagens de arquivo e um ritmo acelerado, cadenciado pela montagem de cortes rápidos. Em pouco menos de quatro minutos, além do mote que dispara a produção do documentário, vemos Grimme comentar sobre algumas questões políticas que remetem direta e indiretamente ao bondage em sua concepção original de técnica de amarração em contextos não eróticos 


\section{(and}

\section{Figura 1: Exército chinês executando criminosos amarrados.}

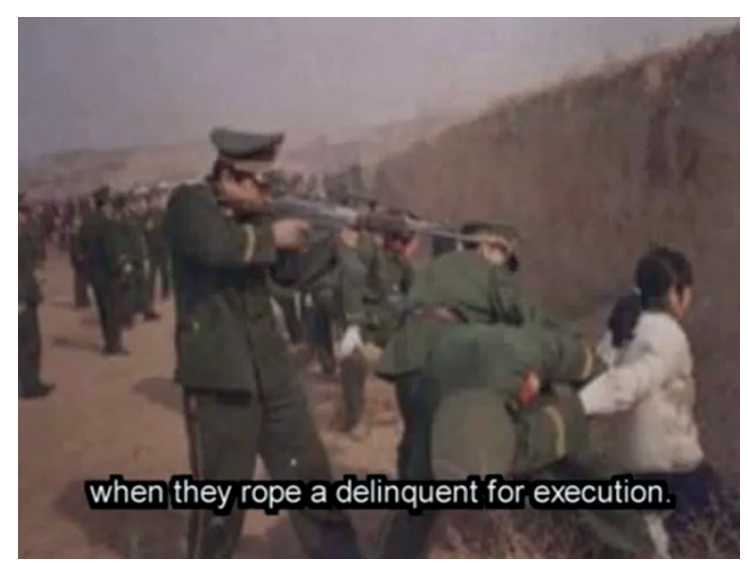

Fonte: Frame do filme Lovely Andrea.

e de violência do Estado. Seus exemplos são o uso de cordas pela polícia chinesa para amarrar e executar criminosos (Fig. 1); amarrações de padrão semelhante ao bondage utilizadas pelos japoneses para deter prisioneiros durante a Segunda Guerra Mundial e a amarração de detentos por cordas na prisão de Guantánamo (Fig. 2).

Após esse prólogo, vemos então Steyerl já em Tóquio, onde reúne uma pequena equipe de pessoas que podem ajudá-la a encontrar a fotografia e tornam-se personagens do filme: Osada Steve, um famoso mestre das cordas alemão que vive no Japão e foi discípulo de Osada Eikichi, um dos grandes mestres japoneses do bondage; e Asagi Ageha, uma performer de bondage que participa do documentário como assistente de direção, tradutora e intérprete, além de fazer algumas performances de suspensão com Osada Steve, registradas por Steyerl e inseridas no filme.

No Japão, Steyerl se filma enquanto vasculha diversos arquivos de fotografias e de revistas especializadas em ensaios fotográficos sadomasoquistas. Também entrevista fotógrafos, ropemasters, equipes envolvidas com a técnica do bondage, editores de revistas e arquivistas. O filme mostra a artista rastreando diferentes conexões que podem a levar à fotografia em uma narrativa fragmentada e bastante experimental, entrelaçando diferentes tipos de imagens, das captadas por ela para o filme às outras colhidas em diversas fontes de arquivos, além de elementos da cultura pop e da cultura underground, videoclipes e trechos de 
filmes ${ }^{28}$. Lovely Andrea, apesar de sua curta duração e fragmentação, consegue abordar as diferentes formas de existência do bondage que foram elencadas anteriormente no texto: prática sexual, performance, trabalho e representação.

O filme permite diversas aberturas para pensar sobre desejo, normatividade e autonomia sobre o corpo se compreendermos, primeiro, que nem tudo relativo ao bondage pode ser lido como pornografia convencional (aquela mais fartamente difundida, que associa o prazer sexual à prática heterossexual, à penetração e ao sexo oral e que estabelece os órgãos genitais como centros exclusivos de prazer). Segundo, que não é preciso estabelecer uma divisão entre antipornografia e pró-pornografia. Terceiro, que a despeito da emergência de discursos feministas no presente que parecem remontar a um "feminismo estatal" (PRECIADO, 2008, p. 238) calcado em uma retórica quase exclusiva da violência de gênero que acaba por reificar posições subalternizadas para as mulheres, a proliferação das multidões e das micropolíticas queer nos anos de 1990 e as estratégias políticas a elas associadas, bem como práticas contrassexuais e as novas formas de prazer-saber "reconfiguram profundamente a forma dos feminismos encararem, produzirem e sentirem a pornografia que, sendo assim subvertida, supera o próprio binarismo antipornografia/ pró-pornografia" (COELHO, 2009, p. 37-38).

É nesse sentido que enxergamos uma aproximação possível entre uma sensibilidade queer em Lovely Andrea e os feminismos dissidentes, para os quais é possível subverter a lógica da pornografia produzindo pornografia a partir de diferentes olhares. É importante esclarecer que os feminismos dissidentes e as micropolíticas queer não são perspectivas pós-feministas ou que pretendem atuar sem o feminismo, "por não se fazerem fora da crítica ao sistema de gênero" (COELHO, 2009, p. 38). Quando Preciado fala em multidões queer, no entanto, refere-se a elas como "resultado de uma confrontação reflexiva do próprio feminismo 'com as diferenças que este silenciava para favorecer um sujeito político 'mulher'

280 título do artigo faz referência à canção Oh Bondage! Up Yours!, da banda punk X-Ray Spex, usada como trilha sonora em diferentes momentos do documentário, que também apresenta alguns trechos de uma performance ao vivo do grupo. A música foi lançada em setembro de 1977 e é considerada uma das canções precursoras do movimento punk na Inglaterra. A sua letra - que é cantada de forma bastante intensa e gritada pela vocalista Polystyrene - trata da possibilidade de escolha da mulher que se submete a um ritual de bondage, da intenção voluntária de ser escrava e vítima - nas palavras usadas na própria composição - e de que forma isso se transforma em uma ação que se potencializa como a voz da mulher que não está ali apenas para ser observada. 
hegemônico e heterocentrado', e sua consequente renovação" (COELHO, 2009, p. 38).

Um dos entrevistados no filme é o editor de revistas Matsumoto Yutaka, que demonstra bastante interesse na busca de Steyerl, afirmando que o mote do documentário, a busca por uma imagem antiga, configura um ótimo mistério. Matsumoto parece se colocar no lugar da diretora e comenta que, em seu primeiro trabalho como editor, ficou nu e amarrado enquanto alguém pingava cera de vela sobre o seu corpo. Para ele o bondage japonês é baseado na submissão, principalmente no sentimento de vergonha. Ele indaga, então: "o que é a vergonha? É a libido no cérebro. Libido, conceito freudiano. Os genitais não estão entre as pernas, estão entre as orelhas, dentro do cérebro". A cena é intercalada com imagens do videoclipe da música Shame Shame Shame, de Shirley and Company.

A fala do editor ecoa outro trecho do filme, em um estúdio fotográfico, no qual acompanhamos parte de uma sessão fotográfica que envolve uma mulher amarrada, caracterizada como secretária. O fotógrafo, Nureki Chimuo, conversa com Steyerl durante o trabalho e se refere à atuação da polícia e à censura contra as representações do bondage em 1987. Embora a publicação de livros e revistas com imagens de bondage remeta pelo menos à década de 1960, o fotógrafo informa que em 1987 a circulação das imagens era bastante restrita e que havia mais trabalho no setor, pois o público parecia se interessar mais quando havia restrições. A proibição aparece na fala dele, então, como ativadora do desejo de consumo das imagens produzidas comercialmente em torno do bondage.

Talvez seja possível afirmar que a consolidação do biopoder no século XX colocou as práticas sexuais dissidentes e desejos não normativos na mesma gaveta da pornografia e do trabalho sexual. Segundo Preciado, a pornografia reúne as mesmas características de qualquer outro espetáculo da indústria cultural e deles difere apenas por estar ainda situada em um "estatuto underground". A pornografia estaria para a indústria cultural assim como o tráfico de drogas para a indústria farmacêutica, como dois motores ocultos do capitalismo do século XXI (PRECIADO, 2008).

Para a autora, a pornografia e a prostituição podem ser consideradas os âmbitos performativos da indústria do espetáculo que foram relegados durante muito tempo ao ostracismo e à ilegalidade: "A transição do corpo monstruoso, perverso ou desviante (freak, homossexual, ninfomaníaca, puta) do estatuto de atração circense ao de doente mental ou criminoso apoiará este processo de exclusão da esfera pública e econômica. 
Figura 3: 0 encontro com a fotografia.

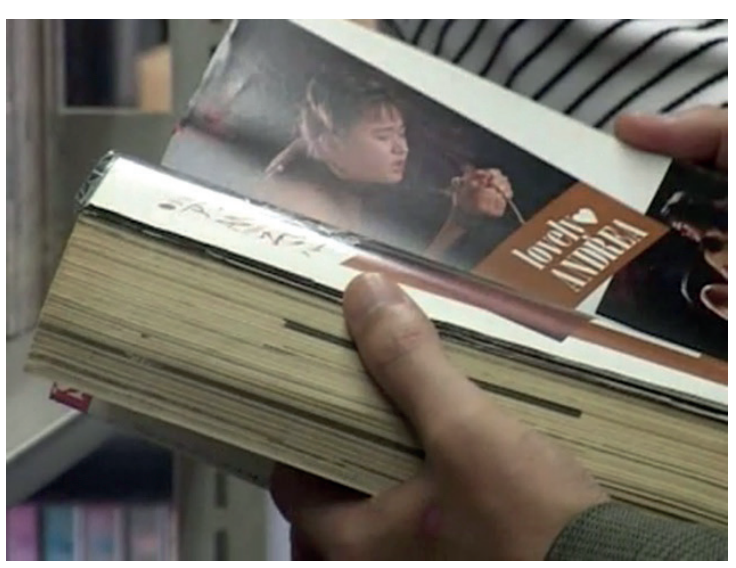

Fonte: Frame do filme Lovely Andrea.

(PRECIADO, 2008, p. 180, tradução nossa ${ }^{29}$, grifo da autora). A pornografia constituiria para Preciado uma tecnologia sexual fundamental, ao excluir as expressões, práticas e corpos que não atendem a um padrão tido como "normal" e aceitável socialmente "na biopolítica global de produção e normalização do corpo" (COELHO, 2009, p. 35).

Em um momento posterior do documentário, Steyerl registra também a visita a um local de armazenamento físico de publicações impressas, onde se filma pesquisando em um acervo de revistas e fotografias de sexo e BDSM. Procura especificamente as revistas lançadas em 1987 até encontrar sua própria imagem: nua,
Figura 4: Detalhe da diretora nua, amarrada e suspensa.

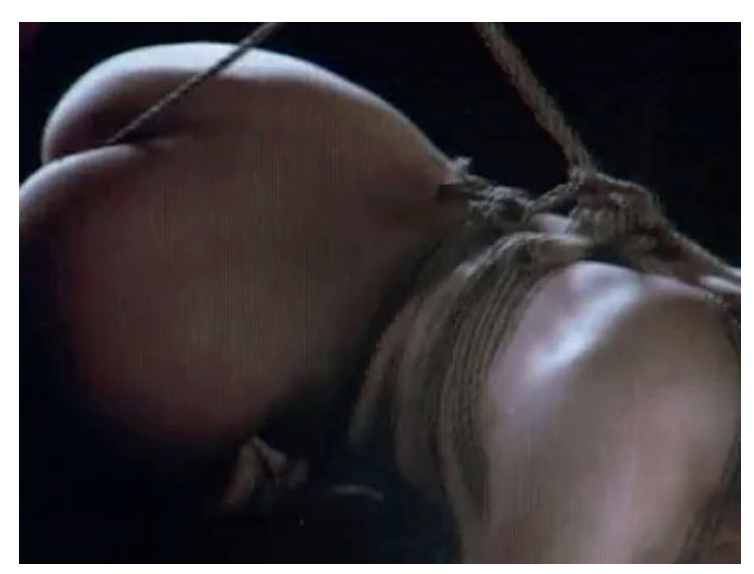

Fonte: Frame do filme Lovely Andrea

amarrada e suspensa (Figs. 3 e 4). Quando alguém lhe pergunta se a foto era documental ou encenada, há um jogo interessante com as cartelas, alternando entre "encenação 1987 " e "encenação 2007", sugerindo que tanto a foto do passado quanto o documentário do presente são encenações/performances.

Se a pornografia que chamamos aqui de convencional é heteronormativa e inviabiliza um lugar de sujeito político para a mulher, a sensibilidade queer a que nos referirmos em Lovely Andrea é colocada nos termos de uma instância autoral que exerce determinado controle criativo sobre a obra e sobre o repertório cultural que circunda о вDSM, bem como sobre 
imagens antigas e sobre o tom autobiográfico que a narração assume em diversos momentos. Mas um entendimento sobre o queer (de forma mais ampla, não apenas como sensibilidade), se faz presente também no modo como as próprias práticas de bondage abordadas pelo documentário se aproximam das práticas contrassexuais, uma vez que não produzem mais do que dor e prazer.

Em Lovely Andrea, Asagi Ageha e Osada Steve são performers de bondage, pessoas que levam a vida fazendo shows e performances em sessões de amarração e suspensão. Em determinado momento do filme, Steyerl registra os dois em plena ação, em uma performance (Fig. 5). Essas imagens são intercaladas com cartelas jogando com as inscrições "bondage é trabalho" e "trabalho é bondage" (LOVELY...,
2007) em meio a imagens do videoclipe da canção She Works Hard for the Money, de Donna Summer, em que mulheres aparecem trabalhando duro em uma fábrica de confecções (Fig. 6).

A ideia do bondage como performance e como trabalho aparece de forma bastante provocadora no filme, em associações que se dão de forma explícita pela fala do personagem Steve e pela montagem que intercala imagens de uma performance e trabalhadoras em uma fábrica. Essa sugestão remete às ideias de Steyerl de circulacionismo e capitalismo audiovisual, em um entendimento de que nada escapa ao capital e de que é necessário, afinal, considerar o bondage como trabalho prioritariamente feminino que pode resvalar também em exploração.
Figura 5: Asagi Ageha em performance de bondage com Osada Steve.

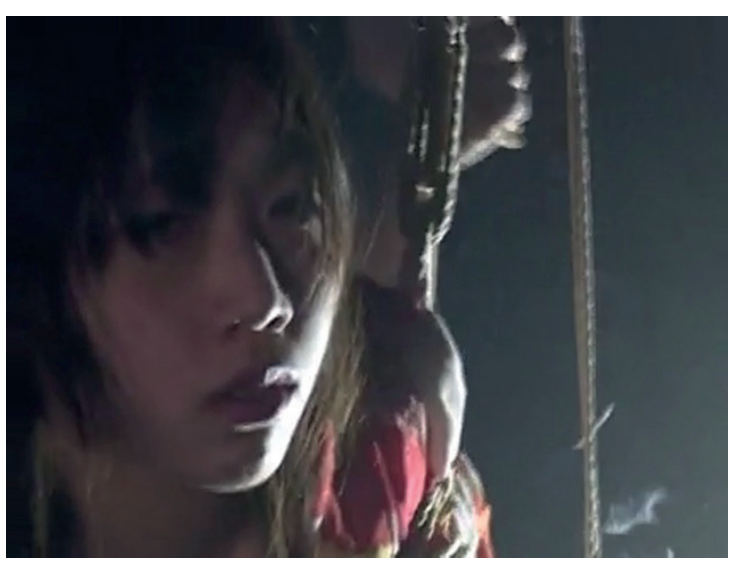

Fonte: Frame do filme Lovely Andrea.
Figura 6: Mulheres trabalhando em cena do videoclipe de She Works Hard for the Money.

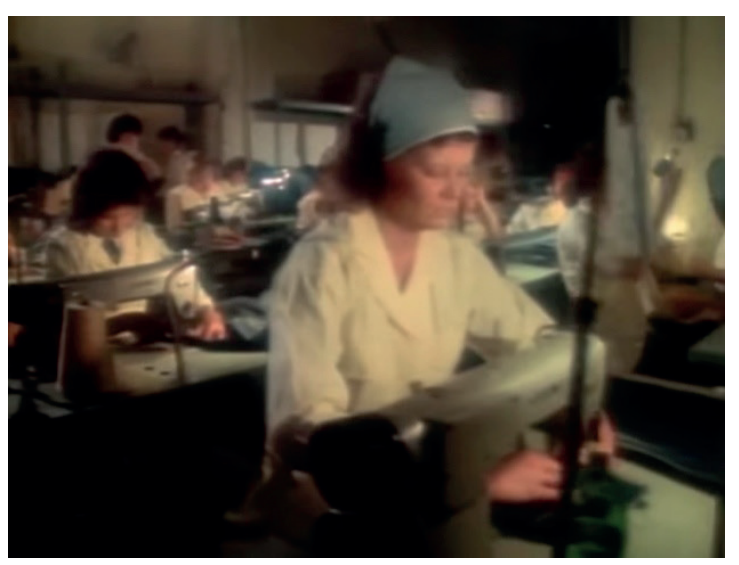

Fonte: Frame do filme Lovely Andrea. 
A abordagem do bondage no documentário como uma prática inscrita na vida cotidiana de uma sociedade e que desliza entre o ato sexual, o trabalho e a representação, permite ainda uma aproximação com a ideia de performance como repetição em Richard Schechner (2012). Para o autor, performances consistem na ritualização de sons e gestos a partir da repetição daquilo que já foi feito e dito antes. Schechner considera que a performance pode ser caracterizada tanto por comportamentos altamente estilizados (como em geral é o caso das práticas artísticas) quanto por atos da vida cotidiana. São ações duplamente exercidas, codificadas e transmissíveis, geradas através de interações entre o jogo e o ritual, um "comportamento ritualizado condicionado/permeado pelo jogo" (SCHECHNER, 2012, p. 49). Performance envolve, assim, ação, interação e relação e, para Schechner, ela não está nas coisas, mas entre as coisas.

Pensar a performance demanda pensar nas variações de ritual, sagrado e secular e compreender que algumas performances são mais conscientes do que outras. Diante das dificuldades em distinguir, na vida cotidiana, o que é ritual, hábito e rotina, é preciso, para Schechner (2012), entender aquilo que envolve as ritualizações e que ele divide em quatro âmbitos: 1) estruturas (como os rituais são vistos e ouvidos, como usam o espaço, quem os realiza e como são realizados); 2) funções (que rituais se realizam por grupos, culturas e indivíduos); 3) processos (dinâmicas subjacentes que conduzem os rituais) e 4) experiências (como é "estar" em um ritual).

Se o bondage passeia de formas muitas vezes indistinguíveis pelos campos do sexo, do trabalho e da representação, podendo eventualmente circunscrever as três instâncias, é por causa essencialmente de sua dimensão performática, que convoca tanto o ritual quanto o jogo, que borra as fronteiras entre real e representação, entre vida cotidiana e estilização. Hito Steyerl não assume para si qualquer capacidade redentora capaz de "resgatar" o bondage e a pornografia do lugar comum - e é possível que tal abordagem esvaziasse, em si mesma, qualquer potencial queer do seu filme. A pornografia é, conforme Preciado, a sexualidade transformada em espetáculo, em virtualidade, em informação digital, em representação pública comercializável que "coloca em marcha um devir-público daquilo que se supõe privado" (PRECIADO, 2008, p. 179180, tradução nossa ${ }^{30}$ ), e Hito Steyerl parece nos convidar a pensar a iconografia do sexo ao colocar em discussão uma fotografia que 
registra uma prática, o bondage, que muitas vezes se dá mesmo no limite entre o público e o privado (já que não é possível saber, por exemplo, se uma fotografia de bondage registra um ritual ou é fruto de um ensaio).

\section{Considerações finais}

Trabalhar com a possibilidade de manifestação de uma sensibilidade queer em Lovely Andrea ajuda a situar a obra de Steyerl em diálogo com a renovação dos feminismos e com o necessário questionamento sobre as tecnologias de gênero e sexo que produzem a diferença sexual, e buscando produzir outras práticas, discursos e desejos. Tanto Steyerl quanto Preciado acreditam que as estruturas sociais e lutas políticas podem ser potencializadas pela mobilização de artistas ou coletivos inscritos em contextos dissidentes (não apenas dissidências sexuais ou de gênero, mas também políticas, econômicas e de outras ordens).

O que a produção escrita e audiovisual de Hito Steyerl dá a ver até o momento, no entanto, é que que o capitalismo audiovisual e o circulacionsmo tornam essencial a articulação de imagens atreladas a discursos que criam ou reforçam práticas sociais e políticas dissidentes para que algum deslocamento seja possível, como a desobediência epistêmica a que ela se refere ou a afirmação de uma estética da resistência.
Consideramos que, ao assumir o bondage em suas diversas formas de manifestação - prática sexual, performance e trabalho e representação - Hito Steyerl, em Lovely Andrea, se aproxima das representações pornográficas "alternativas" cuja potência estaria em mostrar partes do corpo "que foram privatizadas/ silenciadas em prol de uma normatividade heterossexual, bem como as práticas sexuais catalogadas como 'monstruosas' (como o Sado-masoquismo)" (COELHo, 2009, p. 36). A pornografia se transforma, assim, em forma de ação política e, quem sabe, em mecanismo estético de resistência não apenas às normatividades da própria pornografia, mas também do capitalismo e de suas formas de exercício de disciplina e controle, inclusive do desejo, do fetiche e do prazer.

\section{Referências}

BATAILLE, Georges. O erotismo. Porto Alegre: L\&PM, 1987.

BERARDI, Franco. Generación post-

alfa: patologías e imaginários en el semiocapitalismo. Buenos Aires: Tinta Limón, 2016. . Introducción. In: STEYERL, Hito. Los condenados de la pantalla. Buenos Aires: Caja Negra, 2014. p. 11-14.

COELHO, Salomé. Por um feminismo queer: Beatriz Preciado e a pornografia como prétextos. Ex aequo, Vila Franca de Xira, n. 20, p. 29-40, 2009. Disponível em: <http://www. 
scielo.mec.pt/pdf/aeq/n2o/n20a04.pdfs. Acesso em: 10 fev. 2018.

DELEUZE, Gilles. De Sacher-Masoch ao masoquismo. Revista Trágica: estudos de filosofia da imanência, Rio de Janeiro, v. 10, n. 1, p. 95-105, 2017.

Sacher-Masoch: o frio e o cruel. Rio de Janeiro: Jorge Zahar Ed., 2009.

FOUCAULT, Michel. História da sexualidade I: a vontade de saber. Rio de Janeiro: Edições Graal, 1988.

FRANCOEUR, Robert; NOONAN, Raymond. The Continuum complete international encyclopedia of sexuality. Londres: The Continuum International Publishing Group Inc., 2004.

LOVELY Andrea. Direção: Hito Steyerl. Alemanha, 2007, $30 \mathrm{~min}$.

PRECIADO, Beatriz. Manifesto contrassexual. São Paulo: n-1 edições, 2015.

. Mujeres en los márgenes. El País, 13 jan. 2007. Disponível em: $<$ https://elpais.com/ diario/2007/01/13/babelia/1168648750_850215. html>. Acesso em: 12 fev. 2018.

Testo Yonqui. Madri: Editorial Espasa Calpe, 2008.

RICHTER, Hans. El ensayo fílmico. Una nueva forma de la película documental. In: WEINRICHTER, Antonio (Org.). La forma que piensa: Tentativas en torno al cine-ensayo. Pamplona: Gobierno de Navarra, 2007. p. 186189. (Colección Punto de Vista).

RUBIN, Gayle. Reflexionando sobre el sexo: notas para una teoría radical de la sexualidad. In: VANCE, Carole S. (Org.). Placer y peligro:
Explorando la sexualidad femenina. Madrid: Ed. Revolución, 1989. p. 113-190.

SARMET, Érica. Pós-pornô, dissidência sexual e a situación cuir latino-americana: pontos de partida para o debate. Revista Periódicus, v. 1, n. 1, p. 258-276, 2014.

SCHECHNER, Richard. Antropologia e performance. Organização Zeca Ligiéro. Rio de Janeiro: Mauad, 2012.

STEYERL, Hito. ¿Una estética de laresistencia? La investigación artística como disciplina y conflito. Viena: European Institute for Progressive Cultural Policies, 2010. Disponível em:<http://eipcp.net/transversal/o311/steyerl/ es/\#ref>. Acesso em: 12 fev. 2018.

Circulacionismo. Cidade do México: Museu Universitario Arte Contemporáneo/ Universidad Nacional Autónoma, 2014. Em defesa da imagem ruim. Revista Serrote, São Paulo, v. ?, n. ?, p. 184-199, 2015. Is museum a factory? In: The Wretched of the Screen. Berlim: Sternberg Press, 2012. 


\section{Oh bondage! Up yours! Dissident sexualities and non-normative manifestations of desire in the work of Hito Steyerl}

\begin{abstract}
This paper discusses the possibility of agency of a queer sensibility in dialogue with the dissident feminisms in the documentary Lovely Andrea, produced in 2007 by German artist and researcher Hito Steyerl. The film shows the author in Japan, in search of a photograph of herself done twenty years before, in a ritual of bondage. The work is based mainly on the theoretical contributions of Steyerl (2010, 2012, 2014, 2015), Beatriz Preciado $(2008,2015)$ and Franco Berardi (2016) and incites a debate about non-normative manifestations of desire, dissident sexual practices and the politics of images.
\end{abstract}

\section{Keywords}

Sexual and gender dissidences. Queer sensibility. Aesthetics of resistance. HitoSteyerl.

\section{Oh bondage! Up yours! Sexualidades disidentes y manifestaciones no-normativas del deseo en la obra de Hito Steyerl}

\section{Gabriela Machado Ramos de Almeida \\ Doutora em Comunicação e Informação pelo Programa de Pós-Graduação em Comunicação e Informação da Universidade Federal do Rio Grande do Sul. Professora e coordenadora do curso de Jornalismo do Centro Universitário Ritter dos Reis - UniRitter, Porto Alegre, Rio Grande do Sul, Brasil. | E-mail: gabriela.mralmeida@gmail.com ORCID: https://orcid.org/0000-0001-8676-7621}

\section{Jamer Guterres de Mello}

Doutor em Comunicação e Informação pelo Programa de Pós-Graduação em Comunicação e Informação da Universidade Federal do Rio Grande do Sul. Professor do Programa de Pós-Graduação em Comunicação da Universidade Anhembi Morumbi - UAM, São Paulo, São Paulo, Brasil. | E-mail: jamermello@gmail.com ORCID: https://orcid.org/0000-0003-1771-204X

\section{Contribuição dos autores}

Concepção e desenho do estudo: Jamer Guterres de Mello. Aquisição, análise ou interpretação dos dados: Gabriela Machado Ramos de Almeida e Jamer Guterres de Mello. Redação do manuscrito: Gabriela Machado Ramos de Almeida e Jamer Guterres de Mello.

Revisão crítica do conteúdo intelectual: Gabriela Machado Ramos de Almeida. Os autores agradecem a Dieison Marconi pela leitura cuidadosa de uma versão anterior deste artigo, bem como pelas sugestões generosas que contribuíram com o crescimento do trabalho. 